\title{
Scaffolding and Assessing Sustainable Design Skills in a Civil Engineering Capstone Design Course
}

\section{Dr. Elise Barrella P.E., Wake Forest University}

Dr. Elise Barrella is a founding faculty member of the Department of Engineering at Wake Forest University and a registered Professional Engineer. She is passionate about curriculum development, scholarship and student mentoring on transportation systems, sustainability, and engineering design. Dr. Barrella completed her Ph.D. in Civil Engineering at Georgia Tech where she conducted research in transportation and sustainability as part of the Infrastructure Research Group (IRG). In addition to the Ph.D. in Civil Engineering, Dr. Barrella holds a Master of City and Regional Planning (Transportation) from Georgia Institute of Technology and a B.S. in Civil Engineering from Bucknell University. Dr. Barrella has investigated best practices in engineering education since 2003 (at Bucknell University) and began collaborating on sustainable engineering design research while at Georgia Tech. Prior to joining the WFU faculty, she led the junior capstone design sequence at James Madison University, was the inaugural director of the NAE Grand Challenges Program at JMU, and developed first-year coursework and interdisciplinary electives.

\section{Dr. Mary Katherine Watson, The Citadel}

Dr. Mary Katherine Watson is currently an Associate Professor of Civil and Environmental Engineering at The Citadel. Prior to joining the faculty at The Citadel, Dr. Watson earned her PhD in Civil and Environmental Engineering from The Georgia Institute of Technology. She also has BS and MS degrees in Biosystems Engineering from Clemson University. Dr. Watson's research interests are in the areas of engineering education and biological waste treatment.

\section{Mr. Justyn Daniel Girdner, James Madison University \\ Dr. Robin Dawn Anderson, James Madison University}

Robin D. Anderson serves as the Academic Unit Head for the Department of Graduate Psychology at James Madison University. She holds a doctorate in Assessment and Measurement. She previously served as the Associate Director of the Center for Assessment and Research Studies at JMU. Her areas of research include assessment practice and engineering education research. 


\title{
Scaffolding and Assessing Sustainable Design Skills in a Civil Engineering Capstone Design Course
}

\begin{abstract}
As educators seek to incorporate sustainability into engineering courses, appropriate assessment tools are needed to capture the impacts on student development. In particular, methods for assessing student sustainable design skills are lacking in the literature. As a result, we have been engaged in a multi-stage process to develop and validate a sustainable design rubric to both scaffold student application of sustainable design principles, as well as provide a tool to capture students' sustainable design skills. Adapting Benson's Model for construct validation, the first (substantive) stage included producing a set of cross-disciplinary sustainable design principles through review of literature, published rating systems, and reflections from professionals. Currently, we are engaged in the structural and external stages to complete validation of the Sustainable Design Rubric. In particular, we are piloting application of the rubric as a formative design tool in capstone design courses at various institutions to compare intercorrelations between rubric items and expected performance differences between groups.

This paper reports the outcomes of using the Sustainable Design Rubric as a formative assessment in a civil engineering capstone design course at a regional, teaching-focused institution in the Southeast. The assignment was given to 35 students across 7 teams. First, students individually scored their projects for a subset of the criteria - teams divided up criteria amongst their members so that at least two people would score each criterion. Next, students discussed their individual responses with team members to arrive at a set of consensus scores, with written justifications, for all 14 criteria. We reviewed students' responses for appropriateness of scores and quality written justifications as part of the structural and external phases of SD Rubric validation. We found few intercorrelations between criteria within categories (environmental, social, economic), which would traditionally raise questions about structural validity. However, that finding supports that the 14 criteria are distinct and that the Rubric does not contain unnecessary criteria, which further supports substantive validity. We found correlations between criteria from the economic category and each the environmental and social categories. This provides early evidence of external validity, as we expected these correlations across categories since economic criteria specifically ask students to reflect on the economic impacts of addressing environmental and social criteria. Overall, the Rubric seemed to help students grasp what sustainable design "is" or "should look like."
\end{abstract}

\section{Introduction}

The first canon of the American Society of Civil Engineers' code of ethics reminds students, professors, and practicing engineers of the professional responsibility to hold paramount public safety and welfare and "strive to comply with the principles of sustainable development in the performance of their professional duties" [1]. Accordingly, engineering graduates are expected to demonstrate knowledge, skills, and attitudes that will position them to design sustainable 
systems. ABET reinforced this expectation with a special issue brief released in November 2018 and titled "Sustainable Education: Readying Today's Higher Ed Students to Tackle the World's Grand Challenges." The brief describes the landscape of global grand challenges and calls upon engineering educators to provide immersive design experiences that require students' to consider global issues, foster empathy, and recognize the diverse knowledge and cultural awareness required to design and implement modern solutions [2].

As educators seek to incorporate sustainability into engineering courses, appropriate assessment tools are needed to capture the impacts on student development for program improvement and accreditation. A systematic review of the literature revealed a lack of methods for directly assessing student sustainable design skills [3]. Further, the majority of assessment methods, whether direct or indirect measures, have not been validated. Our work tries to address both gaps by developing and validating a rubric to assess sustainable design skills.

We are following an iterative process for defining rubric criteria, structure, and scoring based on Benson's Model for construct validation of tests (a well-regarded method from the assessment field) [4]. We are adapting the model for validation of rubrics. The first (substantive) stage of the Benson Model required producing a set of cross-disciplinary sustainable design principles through review of literature, published rating systems, and reflections from professionals [5]. Currently, we are engaged in the structural and external stages of validation for the Sustainable Design Rubric. The rubric has been tested by two engineering programs, and this paper focuses on implementation in a civil engineering capstone course at a regional, military- and teachingfocused college in the Southeast (The Citadel). Before describing our study's methods and results, we will first summarize literature on assessment validation and our prior work with the Sustainable Design Rubric.

\section{Background}

\section{Sustainability Assessments and Validated Instruments}

A systematic review of ASEE conference proceedings was conducted to identify and discuss the quality of available methods for assessing student knowledge of and interest in sustainability [3]. During the filtering stage, reviewers evaluated records in terms of: (1) whether the study used or presented a tool that assessed interest in, knowledge of, and/or ability to apply sustainability concepts and/or principles, and (2) whether the tool was generalizable to contexts beyond the presented study. After filtering, 29 retained records were categorized according to assessment target: (1) conceptual knowledge about sustainability, (2) ability to engage in sustainable design, or (3) attitudes/beliefs/interests related to sustainability. Results of the systematic review revealed that survey items are most commonly used as indirect measures across all three assessment targets. Furthermore, analysis of records supported that several assessment tools across multiple targets are need to accurately capture the impact of educational interventions on student learning. While rubrics are an instrument used for evaluating student projects, including within civil engineering capstone courses [6], [7], there is a lack of validated and reproducible 
rubrics and other scoring methods for direct assessment of sustainability-related knowledge and skills [3].

The assessment literature puts forward different models for validating instruments, such as surveys and tests, to ensure that the items provide valid, reliable, and sufficient evidence of student learning. A general criticism of rubrics is that they are not adequately validated and do not necessarily provide quality assessment of learning [8]. Benson introduced a widely-cited and adapted model for construct validation [4], which has been applied to assessment instruments across many educational contexts. Benson clearly states the importance of construct validation by describing it as "the most crucial step in test development and use because it is the process by which test scores take on meaning" [4]. Benson's model consists of three stages for developing a strong program of construct validation: (1) substantive, (2) structural, and (3) external. The substantive stage of construct validation involves defining the construct's theoretical and empirical foundations, such that elements of the construct are not excluded (underrepresentation) nor are elements included that are not part of the construct (irrelevancy). The substantive stage involves in-depth review of relevant literature and development of competing hypotheses regarding the construct. The structural stage examines the internal consistency of a specific measure of the construct (i.e., items or subscales) by examining the relationships among observed variables using intercorrelations and factor analysis. During the external stage of construct validation, researchers investigate whether the items or subscales of interest are related to other constructs as theorized. While the Benson model is often employed with the development of tests measures, the model also is relevant for the development of other performance measures, such as rubrics [4]. We have made slight modifications to the methods used in the Benson model to work through the substantive, structural, and external stages in an iterative process that is on-going.

\section{Sustainable Design Rubric}

Our methods for developing the rubric and results from a separate implementation study have been described previously [9]; therefore, only a brief description of the rubric is provided here. The Sustainable Design Rubric currently consists of 14 criteria that address environmental, social, and economic goals for sustainable development and also capture trade-offs and innovative or interdisciplinary approaches to design. The rubric's constructs of sustainable design and their measures are being validated in three phases consistent with the Benson model of construct validity. The first (substantive) stage of the Benson Model required producing a set of cross-disciplinary sustainable design principles through review of literature, published rating systems, and reflections from professionals [5]. Currently, we are engaged in the structural and external stages of validation.

The current version of the rubric template, shown in Table 1, includes space for a 0-3 numerical rating and for each criterion, as well as written justification for each assigned score. In assigning numerical scores, students are encouraged to consider: (1) use of quantitative and qualitative evidence, (2) demonstration of long-term, lifecycle thinking, and (3) applying best practices and 
standards. In composing justifications, students are instructed to list specific examples from their project deliverables (including page numbers when applicable) or undocumented team discussions. Overall, students are guided to provide justifications that are criteria- and projectspecific. An introductory module and worksheets for applying the SD Rubric are available from the research team upon request.

Table 1. Sustainable Design Rubric criteria (version August 2019)

\begin{tabular}{|c|c|c|}
\hline Criterion & $\begin{array}{c}\text { Earned } \\
\text { Points } \\
(\text { /3) }\end{array}$ & $\begin{array}{c}\text { Evidence } \\
\text { supporting } \\
\text { your rating }\end{array}$ \\
\hline $\begin{array}{l}\text { 1. Minimizes the use of non-replenishable raw materials; requires } \\
\text { minimal energy input or uses renewable energy sources }\end{array}$ & & \\
\hline $\begin{array}{l}\text { 2. Minimizes quantity of consumable waste (e.g., water, materials) } \\
\text { output; manages quantity and quality (benign, usefulness) of waste }\end{array}$ & & \\
\hline $\begin{array}{l}\text { 3. Protects or enhances natural ecosystems (water, air, soils, flora, } \\
\text { fauna, etc.) }\end{array}$ & & \\
\hline $\begin{array}{l}\text { 4. Identifies and engages stakeholders (external to project team) in } \\
\text { the design process }\end{array}$ & & \\
\hline $\begin{array}{l}\text { 5. Addresses needs of diverse stakeholders, acknowledging culture } \\
\text { and other differences among individuals and groups }\end{array}$ & & \\
\hline 6. Protects human health and physical safety of users and society & & \\
\hline $\begin{array}{l}\text { 7. Promotes human well-being and enhances quality of life for users } \\
\text { and society }\end{array}$ & & \\
\hline 8. Evaluates economic impacts of environmental design criterion & & \\
\hline 9. Evaluates economic impacts of a social design criterion & & \\
\hline $\begin{array}{l}\text { 10. Considers affordability for users and/or demonstrates cost } \\
\text { competitiveness or cost reduction for client/sponsor }\end{array}$ & & \\
\hline 11. Evaluates economic costs and benefits to inform decisions & & \\
\hline $\begin{array}{l}\text { 12. Final design impacted by trade-offs among environmental, } \\
\text { social, and economic criteria and reflects balance of dimensions }\end{array}$ & & \\
\hline $\begin{array}{l}\text { 13. Uses and/or creates innovation(s) in its specific field to achieve } \\
\text { sustainability }\end{array}$ & & \\
\hline $\begin{array}{l}\text { 14. Worked with experts from other disciplines (i.e., outside } \\
\text { engineering) to enhance process or final design }\end{array}$ & & \\
\hline
\end{tabular}




\section{Methods}

In Fall 2019, 35 civil engineering seniors at The Citadel were recruited to apply the Sustainable Design Rubric to their capstone projects. In place of one of their regular Water and Wastewater Systems classes, students attend an active 1.5 hour session to learn about and apply the Rubric through individual reflection and group discussions. For participating in the session, students earned bonus points on one of the course's design projects. Students were in their first semester of a two-semester capstone project. The students were on seven capstone teams working on an interchange design with transportation, structural, geotechnical, and water resources components. At the time of the Rubric session, students had just selected their preferred alternative (which was different for every group).

Students were asked to apply the Rubric in the context of their preferred alternative, first rating their project individually and then discussing the criteria as a team to arrive at a "consensus" score for each criterion. Students individually scored their projects for a subset of criteria after teams divided up criteria amongst their members so that at least two members scored each criterion. Students received a list of examples related to each criterion and a sample of completed scores with justifications in order to assist with interpreting the criteria and calibrating their scores. After individual scoring, teams discussed each criterion and agreed upon final scores and justifications. To conclude the consensus process, teams were asked to rate the extent (on a three-point scale) to which they considered three factors when rating each criterion: (1) use of quantitative and qualitative evidence, (2) demonstration of long-term, lifecycle thinking, and (3) applying best practices and standards. This final step was added after a previous study [9] showed that students did not consider these factors during scoring.

At the conclusion of the session, students submitted their individual and team project ratings. The instructor, a member of our research team, facilitated the session and answered students' questions about the criteria and scoring process. The instructor had enough time in-class to introduce the rubric, assign criteria to students, complete individual scores, and complete consensus discussions. Students submitted their work before leaving the session. After the session, students were asked to provide feedback on the session and Rubric via an anonymous electronic Google form. All data analysis was conducted by research team members who are not associated with the Civil and Environmental Engineering Department at The Citadel.

\section{Analysis \& Results}

\section{Descriptive Statistics}

We calculated means and standard deviations for students' individual scores and each team's consensus scores, as shown in Table 2 . Students scored themselves highly (>2) on only a few criteria during both individual and team scoring: Physical health and safety (criterion 6), Promoting well-being and quality-of-life (criterion 7), Affordability or cost competitiveness (criterion 11), and Trade-offs across categories (criterion 12). The relatively high ratings for the 
two social criteria (6 and 7) make sense given the capstone project's focus on improving safety, access, and traffic flow in a challenging location. Students consistently cited those goals when justifying the social criteria. All teams were required to consider costs and benefits when choosing their final alternative. Groups often explained that they chose the alternative that would deliver the social benefits, while also costing their client and tax-payers the least, which helps to explain the high scores for Affordability (criterion 11). Students consistently scored themselves relatively low $(<1)$ for the environmental criteria related to conserving natural resources (criterion 1) and minimizing waste (criterion 2). They often explained that the criteria were relevant, but that they had not fully addressed those goals and would be focusing on them more as the project progressed.

Comparing means for individual and team scores shows that scores tended to increase after students discussed each criterion together. For the core criteria (1-11), almost all scores increased, except for Stakeholder Engagement (criterion 4), which remained steady $(M=1.43)$. Standard deviations tended to decrease from individual to team scores which may indicate that team scores were converging. This observation is supported by similarities in team's justifications for their scores, which are discussed in more detail later.

Table 2. Mean and Standard Deviation for Individual and Team Consensus Scores

\begin{tabular}{|l|c|c|c|c|}
\hline \multirow{2}{*}{} & \multicolumn{2}{|c|}{ Individual } & \multicolumn{2}{c|}{ Team } \\
\cline { 2 - 5 } & Mean & SD & Mean & SD \\
\hline 1. Natural Resources & 0.67 & 0.70 & 0.86 & 0.64 \\
\hline 2. Waste & 0.93 & 0.70 & 1.00 & 0.76 \\
\hline 3. Protect ecosystems & 1.83 & 0.92 & 1.86 & 0.64 \\
\hline 4. Stakeholder Engagement & 1.43 & 0.98 & 1.43 & 0.90 \\
\hline 5. Culture and diverse needs & 1.31 & 0.91 & 1.43 & 0.90 \\
\hline 6. Physical safety \& health & 2.33 & 0.79 & 2.43 & 0.73 \\
\hline 7. Quality of life & 2.00 & 0.93 & 2.43 & 0.73 \\
\hline 8. Economic/Environment & 1.47 & 1.02 & 1.57 & 0.73 \\
\hline 9. Economic/Social & 1.38 & 0.74 & 1.43 & 0.73 \\
\hline 10. Costs \& Benefits & 1.79 & 0.86 & 2.00 & 0.76 \\
\hline 11. Affordability & 2.07 & 0.80 & 2.29 & 0.45 \\
\hline 12. Trade-Offs & 2.11 & 0.47 & 2.29 & 0.70 \\
\hline 13. Innovation in field & 1.00 & 0.93 & 0.86 & 0.83 \\
\hline 14. Interdisciplinary experts & 1.14 & 1.36 & 1.14 & 1.36 \\
\hline
\end{tabular}

Note: Green shading indicates an increase in mean score from individual to team consensus while orange indicates a decrease.

\section{Correlations}

Typically, for construct validation of tests you expect to see stronger correlations between items that are related. For our Rubric, it might be expected to see relatively strong correlations between environmental (items 1-3), social (items 4-7), and economic (items 8-11) criteria. A strong correlation would indicate that students scored their project similarly for two criteria; for 
example, criteria 1 and 2 both tended to earn high scores (3) or both earned low scores (0). For our Rubric, however, each criterion was written to be distinct from the others, including within the categories. Applying one environmental criterion to a capstone project does not mean that students are expected to have knowledge of or apply another environmental criterion to the same extent. On the other hand, the dimensions of sustainability are usually described as overlapping or representing "nested dependencies," such that criteria from different categories may be related or impact each other. For this study, all students were assigned the same problem statement and tasks for their capstone project, although each team could develop their own set of alternatives and ultimately select different final concepts. Given the similarities in project context and the students' education, we expected the correlations to show clearer and more easily explainable relationships between criteria. However, we also acknowledged that student attitudes or biases (e.g., favoring environmental protection) may impact scores as much as student sustainability knowledge and skills.

Table 3. Correlations between criteria using team consensus scores

\begin{tabular}{|c|c|c|c|c|c|c|c|c|c|c|c|c|c|c|}
\hline & $1 \mathrm{Env}$ & 2 Env & $3 \mathrm{Env}$ & $4 \mathrm{Soc}$ & $5 \mathrm{Soc}$ & $6 \mathrm{Soc}$ & $7 \mathrm{Soc}$ & 8 Econ & 9 Econ & 10 Econ & 11 Econ & 12 Trade & 13 Bonus & 14 Bonus 2 \\
\hline 1 Env & 1 & & & & & & & & & & & & & \\
\hline 2 Env & 0.89 & 1 & & & & & & & & & & & & \\
\hline 3 Env & -0.05 & 0.3 & 1 & & & & & & & & & & & \\
\hline $4 \mathrm{Soc}$ & 0.35 & 0.42 & -0.14 & 1 & & & & & & & & & & \\
\hline $5 \mathrm{Soc}$ & 0.6 & 0.42 & -0.39 & 0.65 & 1 & & & & & & & & & \\
\hline $6 \mathrm{Soc}$ & 0.75 & 0.78 & 0.13 & -0.06 & 0.16 & 1 & & & & & & & & \\
\hline $7 \mathrm{Soc}$ & 0.44 & 0.52 & -0.18 & 0.37 & -0.06 & 0.46 & 1 & & & & & & & \\
\hline 8 Econ & 0.18 & 0.26 & 0.48 & 0.06 & -0.16 & 0.35 & 0.08 & 1 & & & & & & \\
\hline 9 Econ & 0.75 & 0.52 & -0.48 & 0.37 & 0.37 & 0.46 & 0.73 & 0.08 & 1 & & & & & \\
\hline 10 Econ & 0.3 & 0.5 & 0.3 & 0 & 0 & 0.26 & 0.26 & -0.52 & 0 & 1 & & & & \\
\hline 11 Econ & 0.64 & 0.84 & 0.64 & 0.4 & 0.4 & 0.5 & 0.06 & 0.37 & 0.06 & 0.42 & 1 & & & \\
\hline 12 Trade-Offs & 0.73 & 0.54 & -0.23 & 0.26 & 0.26 & 0.6 & 0.6 & 0.52 & 0.88 & -0.27 & 0.19 & 1 & & \\
\hline 13 Bonus 1 & -0.84 & -0.68 & 0.23 & -0.11 & -0.3 & -0.61 & -0.61 & 0.13 & -0.84 & -0.45 & -0.27 & -0.67 & 1 & \\
\hline 14 Bonus 2 & 0.52 & 0.7 & 0.19 & 0.53 & 0.42 & 0.23 & 0.37 & -0.37 & 0.23 & 0.84 & 0.63 & -0.04 & -0.49 & 1 \\
\hline
\end{tabular}

Note: Green shading indicates a strong correlation and orange indicates a moderate correlation.

The correlations in Table 3 show varying relationships between criteria, reflective of the complexity of the sustainability construct, but there are notable and expected relationships. Within categories the correlations are weak, with the exception of two examples. In the environmental category, there was a strong correlation between criterion 1 (limiting consumption of non-renewable natural resources) and criterion 2 (limiting the amount of and potential harms from waste). This is to be expected because the consumption of natural resources (e.g., fossil fuels, water, solar energy, etc.) often produces waste or by-products that need to be managed and could be harmful to people. Criterion 3 (impacts to natural systems) is less interdependent with the other environmental criteria and thus is not strongly correlated with either. Further, students' evidence for scores $>0$ for Criterion 3 usually focused on disturbance of wetlands, which is quite different than using less energy overall and fewer raw materials (Criterion 1) or minimizing cut and fill and controlling stormwater run-off (Criterion 2). Of the core criteria (1-11), strong and moderate correlations are more prevalent between economic criteria and others, which makes sense because most of the economic benefits and costs of different alternatives relate to, or force a trade-off with, an environmental or social consideration. Similar reasoning also explains the moderate and strong correlations between criterion Trade-offs (criterion 12) and criteria in other categories. 


\section{Evaluation of Student Justifications}

To supplement students' self-assessments, we reviewed the quality of evidence they provided for each criterion. Two members of the research team scored each student justification according to how well it supported their score. The scorers used a system ranging from $0-2$ to indicate varying degrees of specificity and relevance. In this system, a zero score indicated that the justification did not relate to the criterion, was incomprehensible, did not exist, or was not appropriate for the given score. A score of two was reserved for justifications that fully pertained to the relevant criterion, provided sufficient detail on the project, and were appropriate for the student score. In some cases, students' scored themselves lower than the researchers deemed warranted, which resulted in several scores of 1 .

The researchers scored all individual and team justifications separately according to this system before convening to compare scores. Initially, it appeared that there were a number of differing scores between the researchers. This was accounted for, though, by the fact that the researchers used slightly different heuristics to address student scores of zero where minimal justification was provided. Systematically, one researcher assigned a zero to these cases while the other assigned a two. In these instances, the researchers resolved to assign a 1 to all cases where student justification minimally supported a score of zero. Other differing scores between researchers were due to slight differences in interpretation of the justifications or a difference in the degree to which the researcher believed the student addressed the criterion. In many instances of initial score disagreement, researchers shared very similar recorded comments despite a differing score degree. All instances of initial disagreement in score were easily resolved in discussion.

Considering team justifications for their consensus scores $(N=98), 2 \%$ of responses were rated $0,37 \%$ were rated 1 , and $61 \%$ were rated 2 . This indicates that teams' self-assigned scores were for the most part consistent with the evidence they provided. The quality control check supports our finding that the Rubric helped students to formulate their decisions and appropriately score their projects. This was seen the clearest in the team responses to the Tradeoffs criterion (item 12), which reflected varying priorities across teams. Examining the justifications provided in this section, it was apparent that teams explicitly elevated the importance of certain categories above others. For instance, Team 5 aimed to negatively impact "the least of the community and the least of the wetlands" while Team 3 aimed to absolutely minimize impact to the wetland, even going so far as to destroy homes to avoid it. These teams had evidently thought through and deliberated on these tradeoffs before choosing their final alternative. The Rubric provided a structured outlet which allowed them to formalize these tradeoffs between sustainability dimensions.

\section{Discussion}

The Rubric is comprehensive and does seem to help students conceptualize sustainable design, which is sometimes nebulous for them. For example, there were multiple instances in the provided justifications where students mentioned that they would not have thought about certain 
criteria, but that they would account for them in the future. This was particularly relevant among the environmental criteria where nine participants indicated that they had not yet considered the criterion "Minimizes the use of non-replenishable raw materials; requires minimal energy input or uses renewable energy sources" and six indicated that they had not yet considered "Minimizes quantity of consumable waste (e.g., water, materials) output; manages quantity and quality (benign, usefulness) of waste". This indicates that the Rubric is not only acting as a formalizing, but also an informational, dissemination tool by bringing awareness to important design criteria.

Completing the activity in-class was beneficial because the instructor was able to answer questions and observe which aspects of the assignment were helpful versus problematic. Also, the students seemed to put forth more effort in-class than they might have outside of class. The process itself (individual scoring, consensus scoring for each criterion, then weighting the categories) seemed repetitive to many groups. Perhaps this would not have been the case if the activity were conducted in two different sessions, or in-class and then out-of-class. Students did talk about the dimensions (qualitative/quantitative analysis, lifecycle/long-term, best practices/standards), but because there is a fairly long list of criteria, it seemed to become overwhelming to think about all three of those areas for all 14 criteria. We need to identify a new way for students to consider those dimensions, perhaps by incorporating elements of those dimensions into a single scale. The group discussions and scoring seemed to be most beneficial to students and may be prioritized in future implementation of the Rubric, along with deeper consideration of the different scoring dimensions (quantitative and qualitative evidence, lifecycle thinking, and applying best practices). Some students did think about the criteria individually, but because it is a group project, the draw was really to discuss as a group. It seemed that the benefit of the individual time was for students to ask questions about the criteria, and so some time dedicated to individual reading and reflection on the criteria is still warranted.

For this round of testing, we removed the category headings (econ, env, social, etc.) because a previous study indicated that there may not be clear subscales. However, in the second consensus process, students were asked to consider environmental, economic, and social criteria as a group. In addition, two of the economic criteria refer to economic impacts of social and environmental criteria. There was some confusion about the criteria groups with the headings removed. Economic, environmental, and social impacts, in particular, is a well-established framework for conceptualizing sustainability and including the headings could be helpful for students.

\section{Conclusions \& Future Work}

As with our previous implementation of the rubric [9], the criteria seemed to help students grasp what sustainable design "is" or "should look like." The group discussions were very rich and meaningful and may warrant additional time compared to the individual ratings. The rubric and activity would be improved by condensing things further to make information more accessible and impactful. Do we need individual and group components? Do we need all three scoring dimensions? Future changes to implementation may depend on the instructor, students, and desired outcomes. 
The rubric validation process is on-going. From the current study, we found few intercorrelations between criteria within categories (environmental, social, economic), which supports that the 14 criteria are distinct and that the Rubric does not contain unnecessary criteria (substantive validity). In addition, we found correlations between criteria from the economic category and each of the environmental and social categories. This provides early evidence of external validity, as we expected these correlations since economic criteria specifically ask students to reflect on the economic impacts of addressing environmental and social criteria. We are still considering the meaning of intercorrelations (and lack thereof) between criteria within the three theorized categories (environmental, social, economic) based on data from the current study and an earlier one with students from an interdisciplinary engineering program [9].

\section{Acknowledgements}

This material is based upon work supported by the National Science Foundation under Grant No. 1811170 Developing and Assessing Engineering Students' Cognitive Flexibility in the Domain of Sustainable Design. Any opinions, findings, and conclusions or recommendations expressed in this material are those of the authors and do not necessarily reflect the views of the National Science Foundation.

\section{References}

[1] American Society of Civil Engineers, "Code of Ethics", ASCE, 2020. [ONLINE] Available: https://www.asce.org/code-of-ethics/

[2] ABET, "Sustainable Education: Readying Today's Higher Ed Students to Tackle the World's Grand Challenges", ABET, 2018. [ONLINE] Available: https://www.abet.org/wpcontent/uploads/2018/11/ABET_Sustainable-Engineering_Issue-Brief.pdf [3] Watson, M. K., \& Barrella, E. "A Systematic Review of Sustainability Assessments." Proceedings of 2017 ASEE Annual Conference \& Exposition, Columbus, Ohio, 2017. [ONLINE] Available: https://peer.asee.org/27525

[4] Benson, J. "Developing a strong program of construct validation: A test anxiety example." Educational Measurement: Issues and Practice 17, no. 1, 10-17, 1998.

[5] Watson, M. K., \& Barrella, E., \& Cowan, C. M., \& Anderson, R. D. "Validating a Sustainable Design Rubric by Surveying Engineering Educators." In Proceedings of 2018 ASEE Annual Conference \& Exposition, Salt Lake City, Utah, 2018. [ONLINE] Available: https://peer.asee.org/31220

[6] Burian, S. J. "Using a sustainable infrastructure rating system in the civil engineering capstone design course." In Proceedings of the 2014 ASEE Annual Conference \& Exposition, Indianapolis, Indiana, 2014. [ONLINE] Available: https://peer.asee.org/23281

[7] Cecere, J. "Integrating Sustainability in an Engineering Capstone Course." In Proceedings of the 2018 ASEE Conference for Industry and Education Collaboration. August, 2018, San Antonio, TX. Available: https://peer.asee.org/31342

[8] Brookhart, S. M. "Appropriate criteria: key to effective rubrics." In Frontiers in Education, vol. 3, p. 22, 2018. doi: 10.3389/feduc.2018.00022 
[9] Barrella, E., \& Cowan, C. M., \& Girdner, J. D., \& Watson, M. K., \& Anderson, R. "Student Experience and Learning with a Formative Sustainable Design Rubric." In Proceedings of 2019 ASEE Annual Conference \& Exposition, Tampa, Florida, 2019. [ONLINE] Available:

https://peer.asee.org/33293 